Article

\title{
Digital Marketing Actions That Achieve a Better Attraction and Loyalty of Users: An Analytical Study
}

\author{
Juan José López García ${ }^{1, *(\mathbb{D}}$, David Lizcano ${ }^{2}$, , Celia MQ Ramos $^{3}$ and Nelson Matos ${ }^{3}$ (D) \\ 1 Social Faculty, University Distance of Madrid (UDIMA), Vía de Servicio A-6, 15, 28400 Collado Villalba, \\ 28040 Madrid, Spain \\ 2 School of Computer Science, University Distance of Madrid (UDIMA), Vía de Servicio A-6, 15, 28400 Collado \\ Villalba, 28040 Madrid, Spain; david.lizcano@udima.es \\ 3 Escola Superior de Gestão, Hotelaria e Turismo, University of Algarve, 8005-139 Faro, Portugal; \\ cmramos@ualg.pt (C.M.R.); nmmatos@ualg.pt (N.M.) \\ * Correspondence: juanjose.lopez.g@udima.es; Tel.: +34-696-634-589
}

Received: 26 April 2019; Accepted: 5 June 2019; Published: 8 June 2019

\begin{abstract}
Currently, the digital economy contributes decisively to an increase in competitiveness, especially as a digital transformation involves migrating to new technological models where digital marketing is a key part of growth and user loyalty strategies. Internet and Digital Marketing have become important factors in campaigns, which attract and retain Internet users. This study aims to identify the main ways in which users can be gained and retained by using Digital Marketing. The Delphi method with in-depth interviews was the methodology used in this study. The results of the research show the most important actions for achieving user recruitment and loyalty with Digital Marketing from the opinions of consulted experts. The limitations of this study are those related to the number of experts included in the study, and the number of research papers consulted in the literature review. The literature review and the results of this research are used to propose new solid research with a consolidated critical methodology. This research deals with a new approach that will optimize web technologies for the evolution of user trends, and therefore, will be of academic and professional use for marketing managers and web solution developers. The conclusions of the investigation show the key factors, discarding others that do not affect the optimization of conversions in B2C businesses such as the duration of the session and the rebound percentage. Likewise, the results of the research identify the specific actions that must be carried out to attract and retain users in $\mathrm{B} 2 \mathrm{C}$ companies that use the Digital Marketing ecosystem on the Internet. The requirements for companies that wish to implement a model to optimize conversions using the current digital economy are also shown.
\end{abstract}

Keywords: digital marketing; websites analytics; lead generation

\section{Introduction}

It could be said that the Internet has been the factor that has most influenced the cultural, economic and social changes seen at the beginning of the 21st century. Now, the consumer is the focal point of business activities and the target of Internet strategies [1].

Companies provide their customers with positive experiences when using social networks and web 2.0 platforms in order to strengthen their relationships with clients. These companies also need to find out the reasons why customers identify with one brand or another on the Internet [2,3].

Traditional marketing, considered by Kotler as "the identification and satisfaction of the needs of people and society in a profitable manner", constitutes an exchange between consumers and companies in the market, where entities generate value and welfare for customers. However, worldwide Marketing has evolved rapidly in recent years, diversifying the approach, techniques and tools used [4]. 
These modern marketing tools all have ICT (Information and Communication Technologies) integrated into the advertising strategies of companies so that they can compete adequately in the new 2.0 markets $[1,5]$.

Micro, small, and medium enterprises can use this technological business perspective to modernize and acquire the necessary tools to achieve a permanent position in the market and above all in the 2.0 sector, and successfully identify their clients on the Internet [6,7].

Ambler and $\mathrm{O}^{\prime}$ Reilly used these facts to suggest a change from the traditional Marketing model to Marketing using new technologies on the Internet and especially Digital Marketing [8,9]. Currently, in most cases, consumers can easily obtain a lot of information online before making purchase decisions. They have access to suppliers everywhere in the world and also have up-to-date market prices in real time $[5,9]$.

The most modern trend of digital marketing arrives with Kotler, Marketing 3.0 "in the mind of the consumer" [10]. Three years later, Marketing 4.0 "the importance of trust and fidelity" [11].

This has been the incentive for the creation of new Internet marketing strategies such as strategic alliances, exclusive points programs, discounts coupons, banners, and even communication strategies that had not been previously used, such as SEO (Search Engine Optimization), SEM (Search Engine Marketing), SMM (Social Media Marketing) or ASO (App Store Optimization).

Different authors, starting from a traditional base, have developed different strategies that have evolved from traditional Marketing to Digital Marketing. Different institutions have been created in the non-academic research sector to study strategies with these characteristics. Institutions such as the EIAA (European Interactive Advertising Association), the IAB (Interactive Advertising Bureau) or the MMA (Mobile Marketing Association) are examples which show the interest that the business sector has in this area.

In order to show the conceptual and theoretical interest of academic authors in this area of research, the various existing studies into Digital Marketing must also be explained. Authors investigate different types of Digital Marketing strategies with different characteristics [12].

As we have previously noted, the growing use of Digital Marketing as a technique to achieve sales in digital environments has led to a variety of published research in the first decade of the 21st century, "Marketing Communication and the World Wide Web" initiated the scientific study of these technologies and Internet Marketing [13].

In recent years, there has been a lot of academic research published about Digital Marketing. Especially relevant are works [14] in which new ways to advertise on the Internet compared to off-line media are shown [15], Web Analytics can be used in Digital Marketing techniques; the interesting work of Jayaram and Manrai [16] analyzes user behavior with AW on social media, digital campaigns and mobile applications, and the mathematical algorithm proposed to analyze the effectiveness of Search Marketing (Content Marketing) in any sector [17].

Other works show how Digital Marketing has increased business opportunities for companies, and explain how advances in ICT have improved Digital Age Marketing [18]. Nabout, Bernd, Tanja and Gerstmeier make a profitability analysis of Search Marketing techniques [19]. Pierre and Lester propose a measurement model for Digital Marketing techniques when using search engines and the work of Nabout and Skiera show ways to improve the investment made in search engines [20,21].

Research has also been done into the categories and subcategories of Digital Marketing on the Internet. The aim of this research is to understand how users investigate and consequently make decisions to buy goods or services with B2C channels. These channels are influenced by Digital Marketing strategies which have only existed for around 10 years.

This document is organized as follows: the first section contains the literature review. The second section explains the importance of digital marketing. The third section describes the conceptual framework and develops the hypotheses. The fourth section explains the methodology used. The fifth section presents the results found. The sixth and seventh sections show the discussion and the conclusions of the study. 


\section{Related Works}

Net economy is a very important principle. The economy has not changed, but there are new instruments and technologies that support economic processes; the economic use of data networks. It is based on four technological innovations (telecommunication, information technology, media technology, and entertainment) that impact the possible ways in which information, communication and transactions are managed. It refers to the commercial/business dimension of electronic data networks and is therefore a digital network economy. Different electronic platforms perform the execution of information, communication, and transaction processes. The starting point for its expansion is the development of the information society. The basis of the Net Economy is formed by four technological innovations: telecommunication, information technology, media technology, and entertainment. These innovations continue to significantly impact the possible ways in which information, communication and transactions are managed. The increased support of business processes using electronic systems takes center stage here. There are a number of terms for this that can be identified, which can, to some degree, be used synonymously [22,23].

The use of the Internet in the last decade has been one of the most significant examples of globalization. In this new Era of Information and the New Economy, Electronic Commerce (E-Commerce) is one of the main methods for achieving new commercial, labor and social relationships [24].

There are currently a lot of social changes in which new technologies are responsible for changing different aspects of economic and social life. The Internet is constantly being used for new ways of doing business [25].

The quality and performance of business services are improving and are being driven by the use of innovative processes for logistics and the automation of services. Management, quality and speed of data transmissions have become the key factors for competitiveness on the internet [26].

The use of the Internet conditions all stages of the new economy, which, together with Electronic Commerce, offers new ways of doing business such as the new Marketing techniques in the 2.0 environment [1].

Traditional Marketing techniques have evolved to incorporate new Digital Marketing techniques, in which potential customers are considered as users. These users are people who buy or use products and services on the Internet, and who also become prosumers by generating content that interacts with the brand by means of the Internet [27]. Globalization has caused constant changes in which information and knowledge play a prominent role. New business models are being seen in which the traditional concepts of business, customer, taxation, and currency are changing. From a historical perspective, it can be seen that the economy has had to adapt its methods to satisfy the needs of individuals. New techniques have evolved for what some authors consider the New Economy or Information Economy. Global information networks are transforming the world, causing changes in different areas of human activity, such as competitiveness, employment, and quality of life.

Time and distance cease to be obstacles for new technologies. Internet content can be given to a mass audience or a small group of experts looking for a global or local link [28].

Marketing is a form of marketing based on the use of digital media with the aim of structuring direct conversations in which the consumer feels identified [29]. Through Digital Marketing, the aim is to boost the efficiency of commercial actions in these ecosystems. Kotler, Shalowitz, and Stevens, referring to Digital Marketing, define it as, "a social and management process through which different groups and individuals obtain what they need and want, creating, offering and exchanging products with value for others" [30].

The economic and social changes that are associated with globalization give new economic and production characteristics to companies. Producers and suppliers of goods and services have worldwide access to inexpensive transmission of information for commercial or social purposes [31].

One of those changes is being caused by $\mathrm{m}$-commerce. Commerce through mobile phones or tablets (m-commerce) is defined as the purchase and sale of goods and services through wireless handheld devices [32]. We are facing an online commerce adapted to touch screens and with sufficient 
usability levels to be able to complete the sales process of a product from these devices that can be connected to the Internet by mobile phone networks or by WIFI access [33].

The adaptation of e-commerce websites to these devices to increase the number of visits gave way to a new concept: the APP (in English) or mobile application [34]. Also, the social commerce and especially, the collaborative economy is playing an important role in the aforementioned changes.

Thus, for years, there is a similar model like collaborative consumption or social commerce: collaborative economy, although it has some distinctions that characterize it as an economic model of its own. Prior to its appearance, and especially before the Internet and Web 2.0 were born, product exchange was limited to the most immediate geographical area of the consumer [35]. However, there would not be a collaborative economy, as we know it, without the appearance of the web 2.0 technology. Hence, it is the result of taking out of the digital environment the culture created on the Internet for the last fifteen years [36].

The concept of the "sharing economy" is coined under the term "collaborative economy", which began to be mentioned in 2012 in a special way in the tourism sector [37]. Nowadays, thanks to the technologies mentioned before, we can access goods and services from all over the world through four segments: collaborative consumption, contributory production, peer-to-peer finance, and open knowledge. Collaborative consumption is the most widespread and developed segment in the market. On its behalf, the contributory production designs a new industrial peer-to-peer production model, based on the makers movement, the Do-It-Yourself culture (DIY) and the application of the methodological principles of free manufacturing software. The combination of these principles leads to the beginning of a new industrial revolution that democratizes physical production, in the same way that blogs and social networks have democratized content publication [38].

In practice, companies start to use the Internet as a new sales channel, substituting personal visits, mail or telephone calls with electronic alternatives. Digital Marketing, therefore, is an alternative that can reduce costs and is a fundamental tool in business performance. However, the emergence of Electronic Commerce and the development of new marketing techniques questions traditional commerce and gives new problems, while also increasing some of those which already exist.

The fundamental basis for the development of Digital Marketing in the business environment is the Internet. This is the technology that permits the use of electronic marketing techniques and has allowed the creation of the World Wide Web, as we know it today. It is the technology that has allowed the evolution and adaptation of traditional marketing techniques for the new digital environment. A list of definitions of Digital Marketing is given below in Table 1:

Table 1. Definitions of Digital Marketing.

\begin{tabular}{cr}
\hline Author & Definition \\
\hline $\begin{array}{c}\text { American Marketing Association (AMA) } \\
\text { (2013) [39] }\end{array}$ & $\begin{array}{c}\text { Marketing is the activity, set of institutions, and processes for } \\
\text { creating, communicating, delivering, and exchanging offerings that } \\
\text { have value for customers, clients, partners, and society at large. }\end{array}$ \\
\hline Kotlet (2008) [31] & "What a company does to publicize, promote and sell products and \\
services on the Internet."
\end{tabular}

\section{Conceptual Framework and Hypotheses Development}

Due to the rapid changes in Internet and the use of Marketing in the 2.0 environment, there was little academic research about Digital Marketing available until a few years ago. A review of the main research journals dealing with the type of research we are interested in shows that the main topics of research which have been carried out are Digital Marketing, Electronic Commerce, Social Media Marketing, B2C and B2B practices, Email marketing, Digital campaigns, Search Engine Marketing and Optimization (SEM and SEO), Web Analytics for Social Media and Digital marketing, Mobile marketing and Video marketing. 
This study aimed to discover the factors which influence the number of Leads obtained on the Internet by a company. This was done by analyzing the online consumer purchase process. A detailed literature review was undertaken to find out how these factors are used in the main Internet Marketing channels [1]. The actions taken in the online consumer purchase process for Leads acquisition and loyalty were grouped into the following research categories and then studied [15].

Conversions are the actions which the webmaster or web designer wants users to take. Some examples of conversions are purchase, completed form, user registration, subscription to a service, duration of the visit, comment on content, share content, download a document and request a call.

The following hypothesis was proposed after taking into account the above:

H1: The duration of the B2C session affects the number of conversions achieved.

A new user is considered to be a user who visits a website for the first time. In technical terms, a new user is a user whose browser does not have a previously stored cookie [4].

A bounce is a visit to a website that does not connect with the website and immediately leaves it. There are tools that consider a bounce to be a visit only sees one page on the site. However, others consider a bounce to be a visit which is shorter than a number of predefined seconds. Another very important indicator is the bounce rate of a website (globally). This is calculated as the number of rebounds from the total number of visits. It is an excellent indicator of the quality of the contents and how well the audience accepts them, as well as the strategy proposed. Authors indicate that the bounce rate can be calculated for the entire site, for a section or group of contents or for individual content [40].

The following hypothesis was proposed after taking into account the above:

H2: The bounce rate in $B 2 C$ affects the number of conversions achieved.

The number of conversions can be a measure of the success of a campaign and gives information that can be used to act accordingly by either optimizing the campaign content (banners, keywords, and bid strategy) or modifying the daily or monthly investment budget. As seen in the section about non-scientific studies and research into Digital Marketing and Web Analytics; traffic sources are needed in order to analyse the actions made and traffic received on a website.

The following hypothesis were proposed after taking into account the above:

H3: The source of the traffic in B2C affects the number of conversions achieved.

The traffic sources can be categorized for analysis into direct traffic; SEO traffic; SEM traffic; social traffic; display traffic; referred traffic; Emailing traffic and traffic from other sources.

The following hypothesis were proposed after taking into account the above:

H4: SEO and Direct Traffic are the actions that most influence the number of conversions achieved in $B 2 C$ businesses.

SEO is a subcategory within Digital Marketing, highly researched for its impact and its economic value for the company [40].

\section{Methodology}

The Delphi technique was used in this investigation. This technique is one of the research methods used for prospective investigation. Delphi is a prospective method that is considered suitable for analysing opinions made about any topic. These opinions must be made without any pressure or influence from the experts that make up the group. This method means that the results of any consensual study can be validated for the near future [41,42]. The Delphi technique is flexible and uses consensual decision-making by experts for the subject under study. This technique uses a structured process to obtain information from a previously selected group of experts for a range of questions that are important for the subject under research. Self-administered individual questionnaires are presented using web tools and are added to by spontaneous opinions and anonymous comments that can be given at any time. 
Experts never exchange opinions with each other due to the risk that they may influence each other's responses. The Delphi technique systematizes a strategy for the analysis of opinions and comments that can be understood as a type of group interview that has some special characteristics [43]. The Delphi technique is a process that questions a group of specialists (carefully selected previously for their knowledge and professional experience) and uses the answers from successive questionnaires to find consensus of the answers given. The main objective of this methodology is to find a consensus of opinion for the ideas or aims that the investigation proposes [44]. It is interesting to note that the Delphi method, mainly due to the small number of participants—-between 6 and 30—does not produce statistically significant results [45].

The different stages used in the method can be seen in Figure 1.

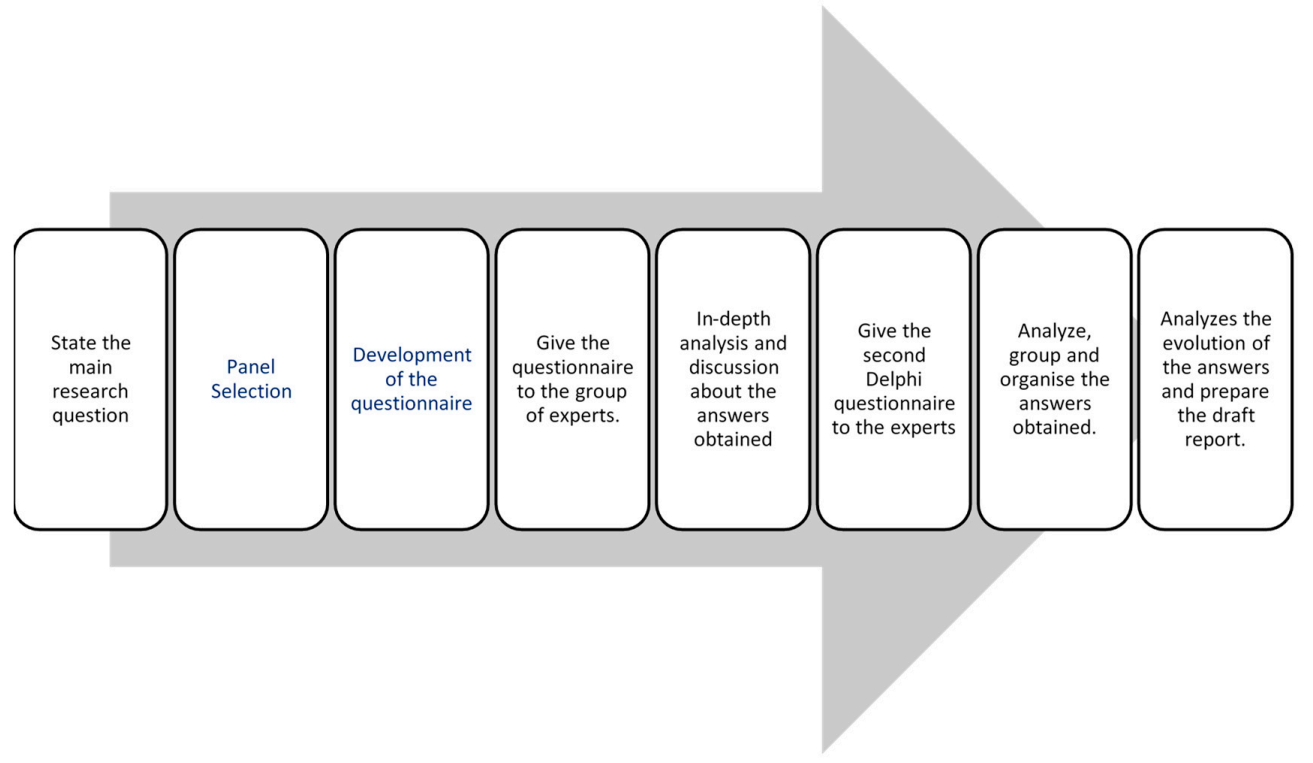

Figure 1. Diagram showing the stages in a Delphi study. (Based on Hsu and Sandford, 2007; Torrecilla-Salinas et al., 2019 [46,47].

First of all, the main research question must be stated. This is designed by a group of experts who are coordinated by the Delphi technique. A protocol must be established to ensure the correct evolution and development of the investigation. Once the main question has been correctly posed, the questionnaire prepared shown in Table A1 (in Appendix A), as Delphi Questionnaire 1 must be given to the selected experts. Once the results of this anonymous process are obtained, an in-depth analysis of the answers is carried out. To do this the group must be structured with the methodology protocol [48]. Then, once the answers to the first questionnaire have been analyzed, a report is made of any answers or opinions that differ from those given by the group. Once the discrepant answers have been analyzed, a second Delphi questionnaire is sent. In order to do this effectively, the conclusions of each round must be expressed clearly and concisely [49]. At this point the Delphi process is repeated again and the questionnaire is sent to the selected panel of experts and the answers are collected. These are analyzed and categorized in order to structure the discrepant responses or opinions about the proposed problems. Afterwards, the answers and the evolution of the comments made by the panel of experts are analyzed and a draft report of the conclusions of the study is prepared. Some authors suggest that this draft report should be given to the panel of experts to ensure that they confirm the results and conclusions of the process [48].

A final report is then prepared in which the evolution of each of the stages and questionnaires in the process are described [48]. In the event that any member of the panel of experts does not agree with something, the Delphi process should repeat the rounds of questionnaires until a consensus is reached. 
The profiles of each of the experts who participated in the Delphi process panel are presented below. Experts from different areas of Digital Marketing were selected to enrich the variety of opinions expressed in the results:

- Professionals from multinationals in the sector, such as Google and Facebook.

- Professionals working in different digital agencies in the Spanish and Portuguese markets.

- Professionals who work in traditional agencies with offline services but also occasionally provide some digital marketing services to their clients.

- Professionals who outsource digital agencies.

- Freelance professionals who provide digital services.

- Professionals who carry out digital marketing actions internally.

This was considered a wide representation of the sector. More than 120 professionals from each digital marketing area were invited to participate. The participation achieved was low, but more than seven experts were found for the group of experts. This means that the results were relevant, as stated in the literature review. Among the most common limitations and weaknesses that the Delphi method involves explain that there is a low potential response. They also point out the cost and the high consumption of time to mold opinions. These days, all these limitations can be overcome thanks to the current speed of electronic communications, email and techniques that that boost the participation of experts (recognitions, improvement of online reputation or publicity of results) [50].

Today, authors such as Heiko, differentiate two main concepts when processing the data collected by Delphi. One of them is "consensus", which means convergence of opinions towards a certain value, and the second one is "stability", which means that values are consistent through different rounds [51]. Dajani, Sincoff and Talley discuss that this "consensus" does not make any sense without "stability" and propose a decision tree to determine stop criteria for Delphi methods, considering both elements. These arguments justify the choice of this method [52].

Regarding the characteristics of the experts consulted: according to gender $83.33 \%$ were men and $16.67 \%$ women. Regarding age, the majority $(77.7 \%)$ was in the age range of 35 to 49 years and $(22.3 \%)$ was in the range of 20 to 34 years. The majority educational level was Master's Degree $(77.7 \%)$, Bachelor's degree $(16.66 \%)$ and Vocational training $(5.55 \%)$. About employment, the majority was Agency managers (83.33\%) and researchers (16.67\%).

The questions asked in the Delphi process were:

A 5-point interval scale was used to evaluate the items in the questionnaire, where 5 gives maximum importance to an item and 1 gives the least importance. Average importance is shown by a value of 3 .

A series of recommendations were followed during the design of the study questionnaire to avoid the common method bias associated with the responses given to a range of different questionnaire questions [53].

Questions using familiar terms for the experts surveyed were asked. Secondly, the confidentiality of the answers was guaranteed so the survey respondent could answer honestly. Finally, random changes were made in the order of the questions to verify that the questions were answered frankly, and not randomly [54].

\section{Results}

The Delphi methodology states that the panel of experts must reach a consensus of opinion for the concepts and questions which are given to them. In this study the panel of experts was made up of 14 people and there were two rounds of questionnaires.

The way the Delphi technique was used to reach a consensus among experts and some of the results obtained are given here. The rest of the results are presented in the discussion section. The first phase for the Delphi question naira asked about the main theoretical concepts for recruitment actions and user loyalty to ensure that the panel of experts identified the concepts [55]. 
The questions in the first Delphi questionnaire were grouped into categories (see Table 2) which were: (i) Capture strategy; (ii) Leads capture strategy in social networks; (iii) User experience; (iv) Strategy for converting clients into repeat clients (loyal customers); (v) Technologies according to their importance for the future of the actions of capturing leads on the Internet, and finally, (vi) Technologies according to their importance for the future of the actions of capturing leads on the Internet.

Table 2. Development of the Delphi method Questionnaire of Delphi survey.

\begin{tabular}{|c|c|}
\hline \multicolumn{2}{|r|}{ Delphi } \\
\hline \multicolumn{2}{|r|}{ Digital Marketing Recruitment Strategy } \\
\hline CA1 & The strategic planning of the recruitment actions \\
\hline CA2 & The elaboration of an annual report of actions for User Capture \\
\hline CA3 & The control and monitoring of each one of the Capture actions carried out quarterly \\
\hline CA4 & The management of the volume of Capture actions according to the number of Leads obtained \\
\hline CA5 & The Digital Marketing department must have a specialist exclusively for the actions of User Capture \\
\hline \multicolumn{2}{|r|}{ Tactics to Capture Leads in Digital Marketing } \\
\hline LA1 & Search Engine Marketing \\
\hline LA2 & Advertising Display \\
\hline LA3 & Email Marketing \\
\hline LA4 & Social Ads \\
\hline LA5 & Video Advertising \\
\hline \multicolumn{2}{|r|}{ Capture Leads in Social Media Marketing on Social Networks } \\
\hline ME1 & Facebook \\
\hline ME2 & LinkedIn \\
\hline ME3 & Twitter \\
\hline ME4 & Instagram \\
\hline ME5 & Others \\
\hline \multicolumn{2}{|r|}{ User Experience for Lead Capture in Digital Marketing } \\
\hline UX1 & Landing page design \\
\hline UX2 & Web page load time \\
\hline UX3 & Number of fields to be filled in the form \\
\hline UX4 & Customized offers \\
\hline UX5 & Colour of objects that represent "calls to action" \\
\hline \multicolumn{2}{|r|}{ Conversion Strategy for recurring customers (loyalty) } \\
\hline LO1 & $\begin{array}{c}\text { Strategic planning of conversion actions for recurring clients is an essential part of the Digital } \\
\text { Marketing plan }\end{array}$ \\
\hline LO2 & The control and analysis of user responses to the loyalty actions carried out \\
\hline LO3 & $\begin{array}{l}\text { In the Digital Marketing department, there must be a specialist exclusively for sending, managing and } \\
\text { controlling the actions aimed at converting customers into recurring customers }\end{array}$ \\
\hline \multicolumn{2}{|r|}{ Conversion of customers into recurring customers (loyalty) } \\
\hline $\mathrm{CO} 1$ & Online after-sales service \\
\hline $\mathrm{CO} 2$ & Gift vouchers \\
\hline $\mathrm{CO} 3$ & Customer rewards (free premium options) \\
\hline $\mathrm{CO} 4$ & E-mail marketing \\
\hline CO5 & Testimonials on the web \\
\hline $\mathrm{CO} 6$ & Discounts/Offers \\
\hline \multicolumn{2}{|r|}{ Future Leads Capture } \\
\hline FU1 & Voice search \\
\hline FU2 & IOT (Internet of Things) \\
\hline FU3 & Mobile World \\
\hline FU4 & Artificial Intelligence (AI) \\
\hline
\end{tabular}


The Delphi methodology was used in two stages and the results of the second questionnaire have already been analyzed to ensure consensus in the panel of experts.

Figure 2 shows that $92.9 \%$ of experts agree that each of the recruitment actions should be controlled and monitored quarterly (sum of the percentage of opinions for options 4 and 5).

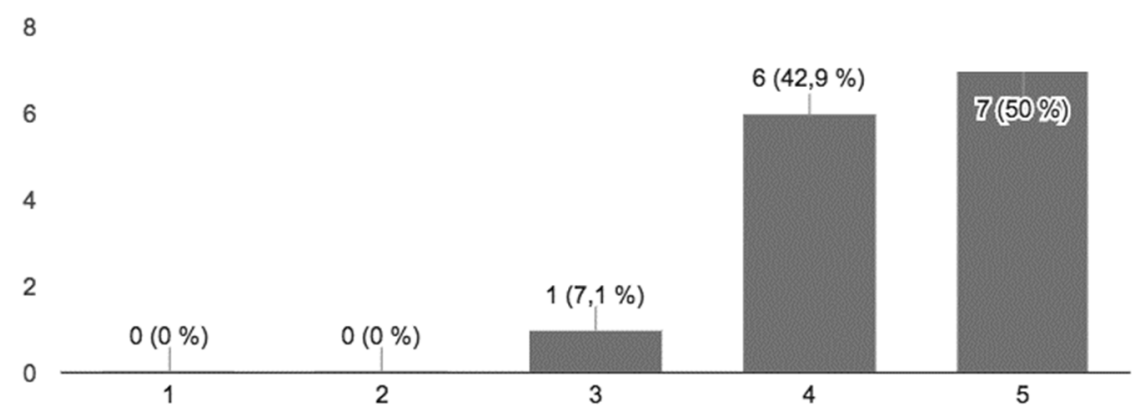

Figure 2. Control and Monitoring of recruitment actions.

In this case, we can see that the panel of experts agrees on the question raised, so the subject is verified, and the Delphi procedure can continue. In the case of the importance of Search Engine Marketing actions used to capture leads on the Internet (see Figure 3), we can see that three of the experts do not agree that it is important for the recruitment strategy. In this case the comment of the expert is recorded, and a comment is made to raise the question again in another way:

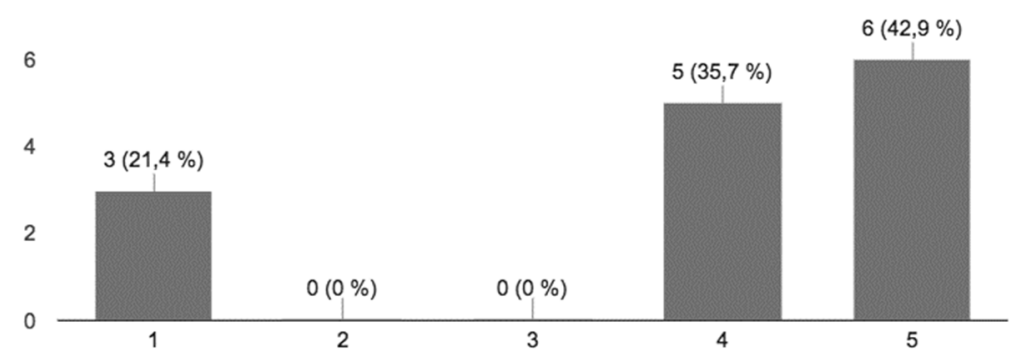

Figure 3. Search Engine Marketing actions used to capture leads on the Internet.

The analysis consisted offending the importance of each Leads recruitment and loyalty channel on the Internet. For example, $64.3 \%$ of the panel of experts believed that Linked In was the best option, followed by Facebook with (14.3\%).

Another result shows the comments given by the experts (see Figure 4). These indicate that Leads can be recruited if the content is structured following the methodology and strategic categories of B2C and B2B. The second round of questionnaires took into account the comments and opinions of the experts from the first round and changed the questions accordingly. The results are shown in Figure 5, where it can be seen that the most effective social network for Leads recruitment in B2C is Facebook (80\% True and $20 \%$ False).

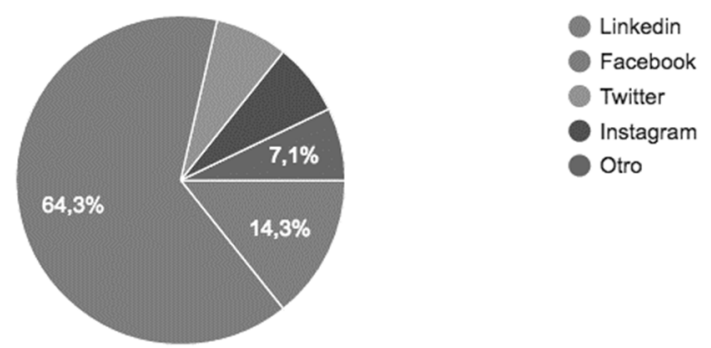

Figure 4. Recruitment using social networks. 


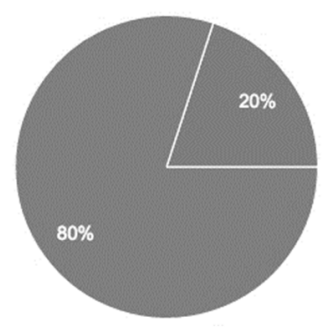

Figure 5. Comparison of leads recruitment on social networks.

The most effective social network for Leads recruitment in B2B is LinkedIn (80\% True and 20\% False). In this case, as a preliminary result we can confirm that the panel of experts agrees. However, using the Delphi methodology, the experts must agree on the comments and opinions which are made. In this study, there was an expert who still did not agree with the statements made in questions 4 and 5 in the second round of questionnaires. When using the Delphi methodology and the decision-making process for each expert in order to agree on comments to reach a consensus, the addition of the expert's ideas at each stage of the process makes the analysis process more complex. In this study, the factors that were taken into account from the questionnaires were those for the actions that promote Leads recruitment and the conversion of recurring clients (loyalty).

The Delphi study was supported by a conclusive statistical analysis. The aim of the quantitative analysis was to show the results obtained from the data sources of the 30 companies in order to see if there was a relationship between the results obtained in the Delphi process and from the in-depth interviews carried out with the experts. Quantitative variables were measured with means, standards, minimum and maximum deviations, histograms and bar graphs. Percentages and sector graphs were used for qualitative or categorized variables. The quantitative data was analysed with a set of statistical techniques in order to understand the data and the relationships which exists between the variables. The quantitative data analysis used simple systematic methods to organize and prepare the data, (i) to detect if errors exist in the design and collection of data; (ii) treatment and evaluation of missing data; (iii) identification of atypical cases (outliers) and (iv) verification of the underlying assumptions in most of the multivariate techniques (normality, linearity, homoscedasticity). This phase of the research process is considered conclusive because it gives objectivity to the study and reinforces the previous research phases.

In the following discussion section, each of the actions under study is considered and the preliminary results of this research are given.

\section{Discussion}

The Delphi methodology was to reach a consensus of opinion about the actions that maximize the recruitment and loyalty of leads in a Digital Marketing strategy for on-line consumers in B2C businesses. The results of the Delphi process were organized into two large groups of actions, which were (i) Recruitment and (ii) Loyalty (conversion of recurring customers). For the first group, the results showed that the actions should be divided into three subgroups:

(i) DDBB. Generation of Leads from actions that use information in Databases.

The actions that use a Database for Leads recruitment could be grouped into two types of strategies: (i) Campaigns on Twitter and (ii) Email marketing campaigns. The Database information can be obtained in two ways: (i) Purchase of quality databases or (ii) Construct a database using the actions mentioned above.

(ii) Advertising (Ads) on social networks.

Two social networks stood out for leads recruitment campaigns, (i) Facebook and (ii) LinkedIn. Although advertising on all social networks works correctly, segments the audience, and achieves 
high conversion ratios, the panel of experts believed that advertising is most effective on two social networks, Facebook for B2C-type businesses and Linked In for B2B-type businesses.

(iii) Special Digital Marketing Actions.

There are two types of special actions for Digital Marketing strategies, (i) Display Advertising and (ii) SEO (Search Engine Optimization) and SEM (Search Engine Marketing).

Display-type actions are effective due to the high amount of segmentation used and the impact on direct audiences. These actions are called RTB actions, although they are commonly known among experts as Display-type advertising. Marketing on Search engines can also be seen to be an effective strategy because it receives the highest amount of business in the digital market in Spain. The most effective strategies are organic positioning of searches and sponsored searches on search engines and blogs.

Loyalty actions (Recurring customer conversions) have two main categories of actions due to their effectiveness: (i) After-sales service and (ii) Email-marketing services.

(iv) After-sales service

There was a complete consensus on this point from the two rounds of questionnaires. The results showed that freemium-type compensation actions are most effective.

When using this type of actions, the business allows customers to test new products or services using a freemium strategy so that the client trusts the business and tries new experiences for free, although the long-term strategy is to turn that user into a premium user of the product offered.

(v) Email-marketing sends

For Loyalty actions (Recurring customer conversions) email-marketing strategies are the most effective as they offer discounts and personalized promotions for each of the segmented groups in the Database (BBDD).

The theoretical framework was confirmed by the feedback obtained from the panel of experts, and then the next stages of the Delphi process started. The panel of experts who agreed to take part was made up of 18 experts from the Digital Marketing industry. The conclusions made from the information and comments given by the panel of experts are given below:

The actions to generate the Database aim to attract Leads in order to contract B2C-type businesses. The experts suggest that the Leads should be gathered with campaigns on Twitter and Email Marketing due to the nature of these social networks. In addition, the Data bases of Leads for B2C-type businesses should use two main channels to obtain the Leads: the purchase of quality databases and the generation of a database of customers that the company has.

The social networks that are most useful for the capture of leads for B2C-type businesses are Facebook and Twitter because they are social networks that share content in a non-intrusive way with advertising campaigns which provide the user with interesting information and content. The social network that the panel of experts preferred for Loyalty actions (actions to convert customers into recurrent/loyal customers) for B2C was YouTube. It is the social network that has the best ratios of content categorization and segmentation as it uses visual adverts which are related to the content a user is watching.

\section{Conclusions}

The results of this study have important practical implications for Managers of Digital Communication Agencies and people responsible for online content and e-commerce stores, as well as for Academics and Researchers.

The results of this research conclude that the future of Leads generating actions in the mobile ecosystem will be influenced by voice searches from mobile devices and the influence of Artificial Intelligence (AI), although the panel of experts indicate that this will happen in the long-term. 
The same situation as for Recruitment actions is expected for Loyalty actions (conversion of recurring customers). In his case however, innovation is introduced using the Internet of Things (IoT).

Experts point out that (IoT) will be less intrusive than certain current advertising actions and that, therefore, it will be consolidated in the future as one of the strategies for user loyalty.

In comparing with other authors from Europe and USA we have evidenced that (AI) and (IoT) is being incorporated in digital marketing actions and probably will be very important in the near future [56,57].

Within the broad ecosystem of possibilities offered by Digital Marketing on the Internet, this research demonstrates and clarifies the specific actions that must be carried out to attract and retain Leads after studying the consumer's on-line purchase process.

The research hypotheses were formulated and then tested by using of the prospective research technique known as the "Delphi method".

The Delphi method is a prospective methodology for finding consensus on any type of short-term future question. This methodology found that the future of Lead recruitment and Loyalty of users for B2C-type businesses must be mobile friendly because of the increase in the use of this technology and the purchasing power of the users. The most influential technologies for Leads recruitment of B2C-type businesses will be Voice Searches and Artificial Intelligence. These must also be Mobile Friendly.

From the results of the study it can be seen that customer loyalty actions (conversion of clients into recurring/loyal customers) improve the results of long-term online recruitment campaigns for B2C businesses. SEO and SEM search engine marketing campaigns should be carried out to attract customers and clients for B2C companies.

It can also be seen that customer loyalty actions (conversion of clients into recurring/loyal customers) for B2C-type businesses should be grouped into two types, (i) After-sales service and (ii) Email Marketing.B2C type businesses should use After-Sales Service with Freemium-type actions or Testing of products because they are highly effective with a high success rate.

Therefore, it is important to analyze how each user's results contribute to the global results in order to determine which measurement has no direct relationship with the achievement of conversions.

Email marketing actions for B2C businesses should use (i) Discounts and (ii) Personalized Offers for the customer. These actions are highly attractive for customers and can provide the company with a lot of useful data and Leads.

The results of this study show that the information for a Database which will be used for Leads recruitment for B2C-type businesses should be obtained with campaigns on Twitter and Email Marketing campaigns.

B2C businesses in the future will use artificial intelligence and Internet of Things (IoT) technology as the most effective Customer loyalty actions. It is very important for companies to have a diversified marketing strategy which includes different digital marketing actions. Companies that sell general products or services should not only focus on one type of audience. They must consider several targets and adapt their message for each of them. This sector is evolving at considerable pace and it is very important to constantly update the strategy.

There are three main limitations to this research:

1. Limitations due to the rapid growth and development of the digital ecosystem and also due to the research sample.

2. As this is a relatively new research category, previous research is relatively scarce, which means that the thorough literature review conducted in this research is of great relevance. The use of the literature review and the results of the research can be used to propose new research with a consolidated critical structure.

3. There is only a moderate participation rate in the Delphi surveys, which although it complies with the established minimums it could be improved. 120 invitations were sent out and 18 participants were obtained. The results could have been more representative with more participants. 


\section{Future Research}

Expansion of the geographical scope. Future investigations could be extended geographically to other countries, given that our research is limited to Spain and Portugal.

Expansion of the digital marketing techniques used. Since digital marketing is constantly evolving some of the emerging techniques may be included.

Future research can use the results of this doctoral thesis to widen knowledge in the analysis of webs, as well as in studies of digital marketing by different disciplines and sectors.

Author Contributions: Designed and wrote the paper, J.J.L.G.; conceptualization, D.L.; methodology, J.J.L.G. and D.L.; investigation, J.J.L.G.; writing-original draft preparation, J.J.L.G.; writing-review and editing, J.J.L.G.; supervised the work, D.L., C.M.R. and N.M. All authors have read and approved the final manuscript.

Funding: This research received no external funding.

Acknowledgments: Thanks to the experts who have participated in the study, and without whose effort and dedication this research would not have been possible.

Conflicts of Interest: The authors declare no conflict of interest.

\section{Appendix A}

Table A1. Guide for the Spanish interview.

\begin{tabular}{|c|c|}
\hline \multicolumn{2}{|r|}{ Interview Guide } \\
\hline \multicolumn{2}{|r|}{ Introduction } \\
\hline \multicolumn{2}{|r|}{ Body } \\
\hline Blocks & Questions \\
\hline $\begin{array}{l}\text { Digital Marketing } \\
\text { (Marketing Digital) }\end{array}$ & $\begin{array}{l}\text { How would you explain the difference between Recruitment and Loyalty of users in } \\
\text { Digital Marketing? } \\
\text { Are the strategies of User Recruitment and Loyalty independent of each other? Why? } \\
\text { What is the importance of the actions of Capturing users in Digital Marketing? } \\
\text { What value do User Loyalty actions have in a Digital Marketing strategy? } \\
\text { What are, in your opinion, the main techniques for attracting users in Digital Marketing? And, if } \\
\text { we talk about concrete actions, what would you highlight? } \\
\text { If we talk about user loyalty techniques in Digital Marketing, which ones could you identify? } \\
\text { Could you high light some specificaction? }\end{array}$ \\
\hline Web Analitics (WA) & $\begin{array}{l}\text { What is the use of the AW in Digital Marketing? } \\
\text { What types of AW or Data can we find in a Digital Marketing strategy? } \\
\text { Should companies establish a measurement strategy based on AW? } \\
\text { With regard to the strategy of User Capture ... What is the function of the AW and why is } \\
\text { it important? } \\
\text { And from the point of view of user loyalty ... What is the use and importance of the AW? }\end{array}$ \\
\hline $\begin{array}{l}\text { Content Design and } \\
\text { Structure (UX) }\end{array}$ & $\begin{array}{l}\text { How would you define the user experience on a website? } \\
\text { How important is the design and content structure of a website in a Digital Marketing strategy? } \\
\text { What graphic elements would you highlight in the design and structure of content in a Digital } \\
\text { Marketing strategy? } \\
\text { If we talk specifically about user experience on the web, what role does the AW develop? } \\
\text { With regard to user loyalty ... What changes exist in the Design and Structure of content? }\end{array}$ \\
\hline $\begin{array}{l}\text { Global Digital Marketing } \\
\text { Strategy }\end{array}$ & $\begin{array}{l}\text { What is the importance of the concepts described above - User Assignment, User Loyalty, AW and } \\
\text { Design and Content Structure - regarding the Digital Marketing strategy? Why is its development } \\
\text { important or not? } \\
\text { How is the Digital Marketing strategy conditioned by these concepts? }\end{array}$ \\
\hline
\end{tabular}

\section{References}

1. Hennig-Thoreau, T.; Malthouse, E.; Friege, C.; Gensler, S.; Lobschat, L.; Rangaswamy, A. The impact of new media on customer relationships. J. Serv. Res. 2010, 13, 311-330. [CrossRef]

2. Kotler, P.; Pfoertsch, W. B2B Brand Management; Springer: Heidelberg, Germany, 2010.

3. Saura, J.R.; Palos-Sanchez, P.R.; Rios Martin, M.A. Attitudes to environmental factors in the tourism sector expressed in online comments: An exploratory study. Int. J. Environ. Res. Public Health 2018, 15, 553. [CrossRef] [PubMed] 
4. Chaffey, D.; Ellis-Chadwick, F. Digital Marketing; Pearson: Harlow (GB), UK, 2016.

5. Palos-Sanchez, P.; Saura, J.R. The Effect of Internet Searches on Afforestation: The Case of a Green Search Engine. Forests 2018, 9, 51. [CrossRef]

6. Järvinen, H.; Laine, M.; Solonen, A.; Haario, H. Ensemble prediction and parameter estimation system: The concept. Q. J. R. Meteorol. Soc. 2011, 38, 281-288. [CrossRef]

7. Palos-Sanchez, P.R.; Saura, J.R.; Debasa, F. The Influence of Social Networks on the Development of Recruitment Actions that Favor User Interface Design and Conversions in Mobile Applications Powered by Linked Data. Mob. Inf. Syst. 2018, 1. [CrossRef]

8. Ambler, T.; Kokkinaki, F.; Puntoni, S. Assessing marketing performance: Reasons for metrics selection. J. Mark. Manag. 2004, 20, 475-498. [CrossRef]

9. O'Reilly, T. What is Web 2.0. Design Patterns and Bussiness Models for the Next Generation of Software. Commun. Strateg. 2007, 1, 17.

10. Kotler, P.; Kartajaya, H.; Setiawan, I. Marketing 3.0: From Products to Customers to the Human Spirit; Wiley: Hoboken, NJ, USA, 2013.

11. Kotler, P.; Kartajaya, H.; Setiawan, I. Marketing 4.0: Moving from Traditional to Digital; John Wiley \& Sons: Hoboken, NJ, USA, 2016.

12. Berthon, P.; Watson, R.T. Marketing communications and the World Wide Web. J. Advert. Res. 1996, 36, 43-54. [CrossRef]

13. Saura, J.R.; Palos-Sánchez, P.; Cerdá Suárez, L.M. Understanding the Digital Marketing Environment with KPIs and Web Analytics. Future Internet 2017, 9, 76. [CrossRef]

14. Pauwels, Z.; Aksehirli, A.; Lackman, A. Like the ad or the brand? Marketing stimulates different electronic word-of-mouth content to drive online and offline performance. Int. J. Res. Mark. 2016, 33, 639-655. [CrossRef]

15. Jarvinen, J.; Karjaluoto, $\mathrm{H}$. The use of web analytics for digital marketing performance measurement. Ind. Mark. Manag. 2015, 50, 117-127. [CrossRef]

16. Jayaram, D.; Manrai, A.K.; Manrai, L.A. Effective use of marketing technology in Eastern Europe: Web analytics, social media, customer analytics, digital campaigns and mobile applications. J. Econ. Financ. Adm. Sci. 2015, 20, 118-132. [CrossRef]

17. Zhuofan, Y.; Shib, Y.; Wang, B. Search Engine Marketing, Financing Ability and Firm Performance in E-commerce. J. Mark. Res. 2015, 55, 1106-1112. [CrossRef]

18. Leeflang, P.; Verhoef, P.; Dahsltröm, P.; Freundt, T. Challengues and solutions for marketing in a digital era. Eur. Manag. J. 2014, 32, 1-12. [CrossRef]

19. Nabout, N.A.; Skiera, B. Return on Quality Improvements in Search Engine Marketing. J. Interact. Mark. 2012, 26, 141-154. [CrossRef]

20. Nabout, N.A.; Skiera, B.; Stepanchuk, T.; Gerstmeier, E. An analysis of the profitability of fee-based compensation plans for search engine marketing. Intern. J. Res. Mark. 2012, 29, 68-80. [CrossRef]

21. Nabout, N.A.; Liliental, M.; Skiera, B. Empirical Generalizations in Search Engine Advertising. J. Retail. 2014, 90, 206-216. [CrossRef]

22. Scuderi, A.; Sturiale, L. Social commerce and marketing strategy for "made in Italy" food products. Ceur Workshop Proc. 2015, 1498, 509-519.

23. Wang, Z. The evolution of social commerce: An examination from the people, business, technology and information perspectives. Commun. Assoc. Inf. Syst. 2012, 31, 105-127.

24. Zhou, Z.; Zimmermann, H.-D. Social commerce research: An integrated view. Electron. Commer. Res. Appl. 2013, 12, 61-68. [CrossRef]

25. Sturiale, L.; Scuderi, A. The digital economy: New e-business strategies for food italian system. Int. J. Electron. Mark. Retail. 2016, 7, 287-310. [CrossRef]

26. Del Águila, R. Comercio Electrónico y Estrategia Empresarial: Modelos de Negocio en Internet; Daccach, T.J.C., Ed.; Alfaomega: Ciudad de México, Mexico, 2000.

27. Ryan, D.; Jones, C. Understanding Digital Marketing: Marketing Strategies for Engaging the Digital Generation; Kogan Page: London, UK, 2009.

28. Maqueira, J.M.; Bruque, S. Marketing 2.0: El Nuevo Marketing En la Web de Las Redes Sociales, 2009. Available online: http://revistacomunicacion.org/pdf/n13/Resenas/R6_Castro-Marketing-2-0-El-nuevo-marketing-enla-Web-de-las-Redes-Sociales.pdf (accessed on 6 June 2019). 
29. Mavlanova, T.; Benbunan, R.; Lang, G. The Role of External and Internal Signals In E-Commerce. Decis. Support Syst. 2016, 87, 59-68. [CrossRef]

30. Chaffey, D. y Wood, S. Business Information Management: Improving Performance Using Information Systems; Prentice Hall: Upper Saddle River, NJ, USA, 2005.

31. Kotler, P.; Shalowitz, J.; Stevens, R.J. Strategic Marketing for Health Care Organizations: Building a Customer-Driven Health System; Jossey-Bass: San Francisco, CA, USA, 2008.

32. Huang, Z.; Benyoucef, M. Usability and credibility of e-government websites. Gov. Inf. Q. 2014, 31, 584-595. [CrossRef]

33. Chong, A.Y.L. Predicting m-commerce adoption determinants: A neural network approach. Expert Syst. Appl. 2013, 40, 523-530. [CrossRef]

34. Palos-Sanchez, P.R. El cambio de las relaciones con el cliente a través de la adopción de APPS: Estudio de las variables de influencia en M-Commerce. Rev. Espac. 2017, 38, 38.

35. Santiago, R.; Trabaldo, S.; Kamijo, M.; Fernández, Á. Mobile Learning: Nuevas Realidades En El Aula; Editorial Océano: Ciudad de México, Mexico, 2015.

36. Palos-Sanchez, P.R.; Correia, M.B. The collaborative economy-based analysis of demand: Study of airbnb case in Spain and Portugal. J. Theor. Appl. Electron. Commer. Res. 2018, 13, 85-98. [CrossRef]

37. Cañigueral, A. Consumo compartido, un nuevo tipo de negocio que juega al alza. Harv. Deusto Mark. Y Ventas 2014, 121, 40-49.

38. Algar, R. Collaborative Consumption. Internet Archive, Wayback Machine. 2007. Available online: http://web.archive.org/web/20130514173126/http://www.oxygen-consulting.co.uk/docs/collaborativeconsump-tion.pdf (accessed on 6 June 2019).

39. American Marketing Association (AMA) (2013). Available online: https://www.ama.org/the-definition-ofmarketing/ (accessed on 7 June 2019).

40. Morgan, A.J.; Chittleborough, P.; Jorm, A.F. Self-help strategies for sub-threshold anxiety: A Delphi consensus study to find messages suitable for population-wide promotion. J. Affect. Disord. 2016, 206, 68-76. [CrossRef]

41. Kaushik, A. Web Analytics 2.0: The Art of Online Accountability and Science of Customer Centricity; John Wiley \& Sons: Hoboken, NJ, USA, 2009.

42. Helmer, O. Looking Forward: A Guide to Futures Research; SAGE Publications: Beverly Hills, CA, USA, 1998.

43. Godet, M. Manuel de Prospective Strategique; Dunod: Paris, France, 1996.

44. Linstone, H.; Turoff, M. The Delphi Method. Techniques and Applications; Addison-Wesley: Boston, MA, USA, 1975.

45. Helmer, O.; Rescher, N. On the Epistemology of the Inexact Sciences. Manag. Sci. 1959, 6, 25-52. [CrossRef]

46. Hsu, C.C.; Sandford, B.A. The Delphi technique: Making sense of consensus. Pr. Assess. Res. Eval. 2007, 12, $1-8$.

47. Torrecilla-Salinas, C.J.; De Troyer, O.; Escalona, M.J.; Mejías, M. A Delphi-based expert judgment method applied to the validation of a mature Agile framework for Web development projects. Inf. Technol. Manag. 2019, 20, 9-40. [CrossRef]

48. Landeta, J. El método Delphi. Una Técnica de Previsión Para la Incertidumbre; Ariel: Barcelona, Spain, 1999.

49. Heiko, A. Consensus measurement in Delphi studies: Review and implications for future quality assurance. Technol. Soc. Chang. 2012, 79, 1525-1536.

50. Parisca, S. El método Delphi. Gestión Tecnológica Y Competitividad. En Parisca, S. Estrategia Y Filosofía Para Alcanzar la Calidad Total Y El Éxito En La Gestión Impresional; Academia: La Habana, Cuba, 1995; pp. 129-130.

51. Dajani, J.S.; Sincoff, M.Z.; Talley, W.K. Stability and agreement criteria for the termination of Delphi studies. Technol. Soc. Chang. 1979, 13, 83-90. [CrossRef]

52. Podsakoff, P.M.; MacKenzie, S.B.; Lee, J.-Y.; Podsakoff, N.P. Common method biases in behavioral research: A critical review of the literature and recommended remedies. J. Appl. Psychol. 2003, 88, 879-903. [CrossRef] [PubMed]

53. Palos-Sanchez, P.R.; Arenas-Marquez, F.J.; Aguayo-Camacho, M. Cloud computing (SaaS) adoption as a strategic technology: Results of an empirical study. Mob. Inf. Syst. 2017. [CrossRef]

54. Chang, S.-J.; van Witteloostuijn, A.; Eden, L. From the Editors: Common method variance in international business research. J. Int. Bus. Stud. 2010, 41, 178-184. [CrossRef]

55. Saravanakumar, M.; Sugantha, L. Social Media Marketing. J. Life Sci. J. 2012, 9, 4444-4451. 
56. Lilien, G.L.; Morrison, P.D.; Searls, K. Performance Assessment of The Lead User Idea-Generation Process For New Product Development; Pubsonline.Informs.Org: Catonsville, MD, USA, 2002.

57. Rodriguez, M.; Peterson, R.M. The role of social CRM and its potential impact on lead generation in business-to-business marketing. Int. J. Internet Mark. Advert. 2012. [CrossRef]

(C) 2019 by the authors. Licensee MDPI, Basel, Switzerland. This article is an open access article distributed under the terms and conditions of the Creative Commons Attribution (CC BY) license (http://creativecommons.org/licenses/by/4.0/). 